\title{
Prof. Dr. Gerhard Seifert (1921-2014): a European pathologist from Germany
}

\author{
Günter Klöppel
}

Received: 1 September 2014 / Accepted: 8 September 2014 / Published online: 7 October 2014

(C) Springer-Verlag Berlin Heidelberg 2014

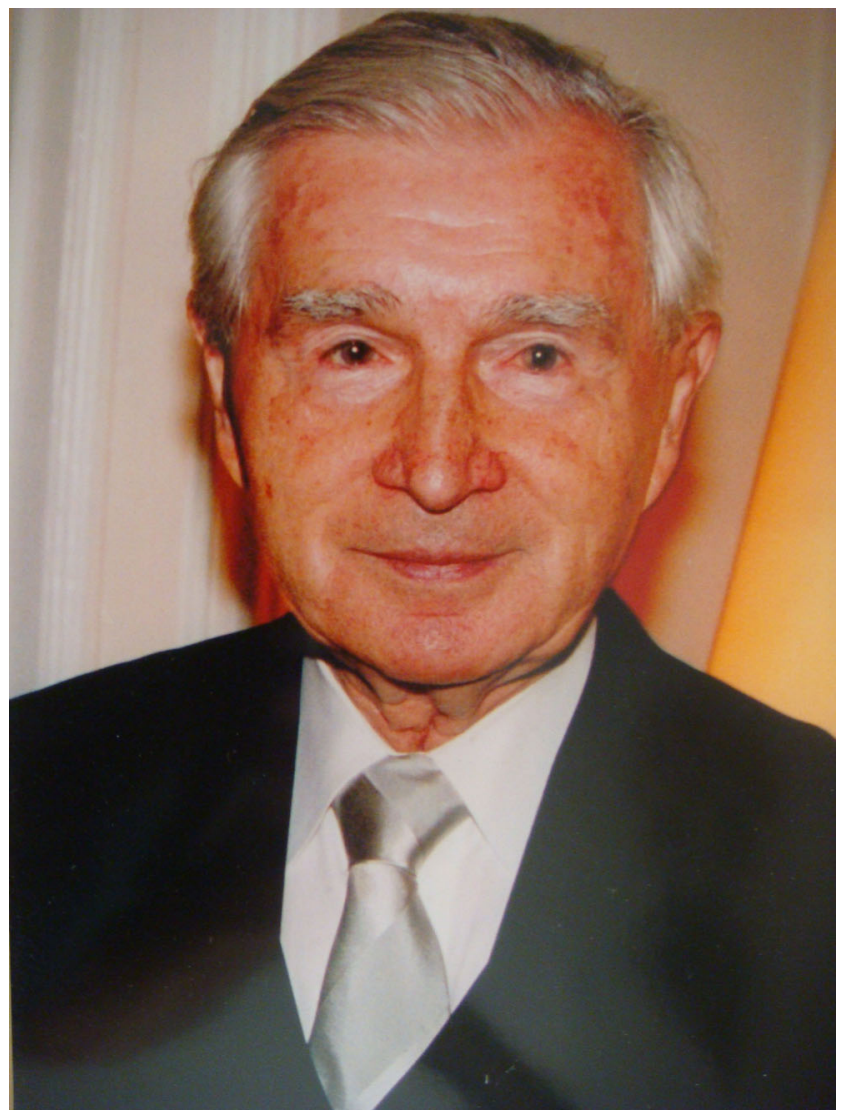

Gerhard Seifert died on April 17, 2014, in Hamburg. For more than a year, he had suffered from repeated severe cardiac attacks. However, he lived on his own and was very agile

\section{G. Klöppel $(\bowtie)$}

Konsultationszentrum für Pankreas- und endokrine Tumore Prof. Dr. med. H. Höfler und Prof. Dr. med G. Klöppel Institut für Pathologie TU- München, München, Germany e-mail: guenter.kloeppel@alumni.uni-kiel.de mentally, still enjoying music, books, even short trips, and contacts with his friends and former pupils, until in March 2014, the cardiac disease that led to his death began to progress rapidly.

Gerhard Seifert was born in 1921, in Leipzig, Germany, where he grew up, went to school, and enrolled in the Medical School of the University. In 1940, he passed his final school examination, and in 1947, he graduated with a degree in medicine and completed his doctoral thesis. After a short term in clinical medicine, he began training as a pathologist at the University Department of Pathology in Leipzig under the supervision of Professor Heinrich Bredt. There he specialized as a pathologist and qualified as "Privatdozent" in 1955. In 1958, he left East Germany for Münster, West Germany, where he joined the University Department of Pathology, headed by Professor Willy Giese. There he strengthened his skill as a surgical pathologist, continued his research, and was appointed associate professor in 1961. In 1965, he became a full professor of pathology and the holder of the prestigious chair of the Department of Pathology at the University Hospital Eppendorf in Hamburg as successor to Karl Krauspe, one of the founders of the European Society of Pathology. For 23 years he was the head of this institution. During this period, he modernized surgical pathology and developed research projects with his pupils, in the process making the department one of the best known centers of pathology in Germany, with a focus on oral pathology, salivary gland pathology, pancreas pathology, endocrine pathology, and osteopathology. He himself became known as an outstanding salivary gland specialist. As such, he was one of the founding members of the working group on head and neck pathology of the European Society of Pathology and an organizer of a "salivary gland registry" in Hamburg, which he continued to serve as a consultant after his retirement.

He was a member of various societies, and in recognition of his scientific work, he received many honors. Here I shall 
only mention the membership in the German National Academy of Sciences "Leopoldina", the Virchow medal of the German Society of Pathology, and honorary memberships of the German and European Societies of Pathology.

What was special about Gerhard Seifert? As a pathologist he was accurate, quick, and precise, and if there was a problem that he was unable to solve by himself, he immediately consulted his specialists in the department in order to come to a consensus solution. His aim was to deliver the diagnosis to the patient in the shortest possible time. And the patients and their clinicians were grateful to him.

As a researcher, he had a broad interest in many fields of pathology, including the diseases and particularly the tumors of the salivary glands, the oral cavity, the pancreas, the endocrine glands, and the bone. Most of his publications - and together with his collaborators, he wrote more than 400 articles-focused on the recognition of disease features that would help to improve the diagnosis or characterize a new disease entity. In pursuing this aim, he made use of all the new technologies that were becoming available, such as immunohistochemistry. With this work, he gained international reputation and contributed greatly to the development of the WHO classification of salivary gland tumors, which appeared in 1991 under his leadership.

As a teacher and writer, his outstanding trait was his focused, systematic, and concise presentations and publications. Disciplined, reliable, and prolific as he was, he was one of the very few scientists who were never too late with their contributions. He also managed to write his memoirs, which meticulously recorded all of the steps in his life and even his poems.

As an editor, he was helpful, but also critical, always seeking to improve what was worthy of being recorded. He was the editor or co-editor (together with W. Doerr and E. Uehlinger) of a number of textbooks and textbook series (such as the 22 volumes of the "Spezielle pathologische Anatomie") and he was the joint managing editor of Virchows Archiv A (together with Sir Colin Berry, London) from 1986 to 1994, when Virchows Archiv A and B merged. In his function as editor, he had close connections to the publisher, Springer, and was honored on his 65th birthday with a special issue of Virchows Archiv that included articles by his collaborators (Virchows Archiv A Pathological Anatomy and Histopathology 409, 1986).
As chairman of societies and scientific committees, he, a man of integrity, great friendliness, and modesty, is well remembered for his efficient leadership and pragmatic decisions. He was the president of the German Society for Digestive and Metabolic Illnesses (1977-1978), the German Division of the International Academy of Pathology (1979-1985), the German Society of Pathology (1985-1986), and the European Society of Pathology (1985-1987). In Hamburg, he organized two successful congresses, the 10th congress of the International Academy of Pathology in 1974 and the 9th European Congress of Pathology in 1983. After his retirement, he served as the president of the Joachim JungiusGesellschaft der Wissenschaft, the Hamburger Stiftung zur Förderung der Krebsbekämpfung, and the Freundes- und Förderkreis des Universitätsklinikum Hamburg-Eppendorf.

As head of the department and administrator, he aimed at an administrative structure and atmosphere that allowed efficient work at all levels. Problems were usually tackled immediately and, tolerant as he was, they were solved in a way that everybody could live with. Thus, over the years, he became the "first servant of his institution," and a father and example to all members of the department.

As a mentor, he was stimulating and supportive, and as a friend, he accompanied and kept contact with all who had once worked with him. He had his regular meetings with his old colleagues from Leipzig and Münster, and every year - up to the last year of his life - he assembled his former collaborators (the so called "Habips") for dinner in Hamburg.

Gerhard Seifert was religious, but at the same time, he stood with both feet very much in this world. He always looked forward and enjoyed his busy life. When he really relaxed, he read books about science and history, listened to music, particularly by Bach, and played the piano. For recreation, he hiked through the Black Forest. All these activities were shared by his wife Leonore and his two sons, Andreas and Christoph. Unfortunately, Leonore and Christoph passed away early. In his last decade, Marlies Esser lived by his side. Together they enjoyed traveling and the great cultural events of Hamburg, which was his home for 49 years.

He was a great European pathologist from Germany and a faithful friend. He will not be forgotten

Günter Klöppel München, August 2014 